\title{
OBESITY AND CHILD HEALTH: RESULTS FROM AN IRISH LONGITUDINAL STUDY EVALUATING A HEALTH PROMOTING MANUALISED INITIATIVE
}

\author{
E. Hollywood, C. Comiskey
}

School of Nursing \& Midwifery, Trinity College Dublin, Dublin, Ireland

Background: In the Republic of Ireland the National Children's Strategy (2000) calls on the all agencies to work to improve the quality of children's lives. A health promoting manualised initiative was developed for implementation in disadvantaged schools.

Aim: The aim of this research is to measure and model the body mass index of each participating child on an annual basis as this is one of the key physical outcomes of the manualised initiative.

Method: A three year longitudinal comparative evaluation of the initiative was carried out between 2009 and 2011. Five intervention and two comparison schools were recruited. Quantitative health data was collected on each participating child to determine their BMI at baseline, year 1 and year 2. Ethical approval was granted and procedures for child protection and disclosure were agreed in advance.

Results: Participation rates within schools were over 50\%. The computation of BMI by school type and by gender and age was also computed for all children. Overall within the intervention schools it was observed that over one quarter $(27.8 \%=19.1 \%+8.7 \%)$ of all children were either overweight or obese. Similar results were observed within the comparison schools which found that $28.9 \%$ of all children were either overweight or obese.

Conclusion: BMI rates of overweight and obesity among young females were of concern. Longitudinal outcomes are still in progress; however baseline results reveal that the health and wellbeing of children attending disadvantaged schools is in line with European norms with the exception of BMI among pre teens. 